This article has been published in a revised form in Ageing and Society https://doi.org/10.1017/S0144686X1900117X. This version is free to view and download for private research and study only. Not for re-distribution, re-sale or use in derivative works. (C) Cambridge University Press 2019.

\title{
Transforming lived places into the connected neighbourhood: a longitudinal narrative study of five couples where one partner has an early diagnosis of dementia
}

\section{Abstract}

$\underline{\text { Xia Li, John Keady, and Richard Ward }}$

To support people with dementia to live at home, a key national and international policy driver is to create dementia-friendly communities that draws attention to the importance of a local neighbourhood and living well with dementia. However, there is a lack of evidence about how people with dementia define and interact with their neighbourhood. This longitudinal narrative research aimed to uncover the meaning, construction and place of neighbourhood in the lives of people with dementia and their care partners through a participatory approach. Five couples, where one partner had an early diagnosis of dementia and capacity to consent, participated in the (up to) one-year mixed qualitative method study. During this timeframe, 65 home visits were conducted, resulting in over 57 hours of interview data alongside the development of other artefacts, such as neighbourhood maps, photographs, diaries and field notes. Narrative analysis was applied within and across the datasets. This led to the emergence of three themes to describe a connected neighbourhood. First, 'connecting to people' is about the couples' connections with family members, friends, and neighbours through a sense of belonging, group identification and responsibilities.

Second, 'connecting to places' shares the couples' emotional and biographical attachment to places. Third, 'connecting to resources' refers to the couples actively seeking support to live independently and to retain neighbourhood connections. 


\section{Background}

The rapid increase of the ageing population has led to a growing number of people living with dementia, with the probability of developing a dementia almost doubling every five years after the age of 65 (Department of Health 2015). In the United Kingdom (UK), there are approximately 850,000 people living with dementia (Alzheimer's Society 2017), and of which around two thirds live in their own homes (Alzheimer's Society 2013). Whilst such demographics are of value, the meta-narrative of 'living well with dementia' has become a key goal in the World Health Organisation's (WHO) global action plan on dementia on the public health response to dementia 2017-2025 (WHO 2017). Key building blocks of the 'global action plan on dementia' are the protection and communication of human rights for people living with dementia and the creation of dementia-friendly communities (see also: WHO and Alzheimer's Disease International 2012). In the UK, the setting up of dementiafriendly communities has become one of the government's strategic priorities in both of the Prime Minister's Challenges on Dementia (Department of Health 2012, 2015). This initiative has drawn attention to the significance of a local neighbourhood and its place in dementia studies (Keady et al. 2012).

Historically, a 'neighbourhood' has been viewed as a multi-dimensional place where residents live and interact with various properties, operating within a geographical boundary; for example, La Gory, Ward and Sherman (1985) define a neighbourhood as:

... a physical, social, and cultural setting affecting the choices and actions of its residents. Indeed, the degree to which neighbourhoods are congruent with the capacities and needs of inhabitants appears to affect the residents' quality of life, as well as the local community's dynamics. (p.406) 
In this respect, a neighbourhood is seen to be a 'lived place' that helps to explain the relationship between people and the environment (Baker 1968). It is this person-environment dynamic, situated within an everyday context, that closely relates neighbourhood living to health status (Satariano 2006) and, in particular, to social health (Huber et al. 2011), which involves making a "dynamic balance between opportunities and limitations, affected by external conditions such as social and environmental challenges" (Vernooij-Dassen and Jeon 2016, p.701). This association is further enhanced by the fact that the neighbourhood provides a setting for social cohesion (Dempsey 2007) which is the stock of an individual's investments in social contacts that provides personal and social benefits (Oxoby 2009). Indeed, the Office of the Deputy Prime Minister (2002) suggests that socially cohesive behaviours and attitudes should be aligned to a high quality of neighbourhood living.

Given these layers as context, being in a 'neighbourhood' can have double-edged impact upon the experiences of people living with dementia (Górska et al. 2018). For instance, familiar environments can enable their engagement with outside spaces and places, whereas unfamiliar environments can disable the person with dementia's outdoor activities and social interactions (Brittain et al. 2010; Duggan et al. 2008). It is this fluidity of experience that affects everyday living and a sense of social cohesion (Górska et al. 2018; Keady et al. 2012). Indeed, over time, and as the dementia progresses, the changing health and cognitive abilities can influence a sense of familiarity which results in previously familiar place becoming unfamiliar. This leads to a question: what is it like to live in a 'neighbourhood' as a person living with dementia when there is a significant risk that (s)he could act in a way that is detrimental to socially cohesive behaviours, such as frequently becoming lost in seemingly familiar places? This is especially evident when getting 'out and about' and walking around the neighbourhood is seen to contribute towards a person living with dementia's sense of 
independence, self-respect and social contact (Keady et al. 2012; Mitchell and Burton 2010; Odzakovic et al. 2018).

It is this conflicting position that has stimulated interest in a 'person-in-environment' approach to dementia studies in order to better understand the complex relationships and inter-relationships that are happening in such everyday settings (Blackman 2006; Duggan et al. 2008; Huber et al. 2011; McGovern 2016; Tranvåg, Petersen and Nåden 2015; Ward et al. 2018; Wiersma and Denton 2016). Generally speaking, transforming spaces into meaningful places derives from using spaces over time, so forming patterns of familiarity and comfort, which contribute towards the development of an emotional attachment and a sense of ownership (Rowles and Bernard 2013). Attachment to places can then be intensified where significant life events occur with these places representing identity; consequently, places contain multifaceted layers of meanings, becoming potential sources of self-affirming recollections (Rowles and Bernard 2013). The outcome of the accumulation and assimilation of layer upon layer of meanings in place can be defined as a sense of being in place in which identity and belonging are secured and an assumption of stability facilitated (Massey 1994; Peace 2013; Rowles and Bernard 2013). More specifically, at a neighbourhood level, people living with dementia can make their own places through capitalising on local assets to promote their well-being and social health (Pierce et al. 2011).

The abilities and assets that people living with dementia have in managing their everyday environment, and in making their own meaningful places, demonstrates the person's potential to continue to be active citizens (Bartlett and O'Conner 2007; Kelly and Innes 2013; O'Connor and Nedlund 2016). Indeed, under the umbrella of citizenship, social citizenship is defined by Taylor-Gooby (2008) as "the rights and duties associated with the provision of benefits and services designed to meet social needs and enhance capabilities" (p. 3) with Bartlett and O'Connor $(2007,2010)$ conceptualising social citizenship as a status, practice 
and relationship and grounded these aspects in dementia through a set of rights and responsibilities. More recently, Bartlett and Brannelly (2018) have applied social citizenship and care to people with dementia's experiences of living in their own homes, particularly relating to social justice and interpersonal relationships. They also point out the need for shifting the trend of the institutionalisation towards a deinstitutionalisation perspective, emphasising the significance of developing community-based services to support people with dementia to live at home in line with their rights and preferences.

These factors draw attention to how citizenship-based approaches fit with the increasing interest in dementia-friendly communities and neighbourhood-level research (Bartlett 2014; Harding et al. 2018; Tampubolon et al. 2018; Ward et al. 2018). It is at this intersection that the present study is situated, taking a subjective and inductive approach to explore, over time, the in-depth meaning, construction and place of 'neighbourhood' in the everyday lives of five people with dementia and their care partners using a mix of qualitative approaches, as will now be outlined.

\section{Methods}

Participants and setting

Purposive sampling was used to recruit five couples, where one partner had an early diagnosis of dementia measuring a cumulative scoring total of around 20 or higher (maximum score 30) on the Mini-mental State Examination (MMSE; Folstein, Folstein and McHugh 1975) and as administrated by their clinicians. This ensured that, at the time of recruitment, people living with dementia were able to give informed consent to take part in the study using a 'higher' (around 20 and above) MMSE score as a measure of capacity 
(British Psychological Society 2015; National Institute for Health and Care Excellence 2006; Pezzotti et al. 2008). Other inclusion criteria applied to the study were: the person with dementia living in their own home with a care partner; able to get out and about in their neighbourhood; and spoke English. Care partners were eligible for inclusion if they were: living with the person with dementia; aware of the diagnosis; and nominated as a care partner by the person living with dementia.

The lead author worked closely with two Community Mental Health Teams for Older People in the East Midlands area of the UK who helped select potential participants, according to the study protocol. The recruitment process took approximately 14 months and initially identified seven couples who met the inclusion criteria and expressed an interest in participation. Of these, five couples gave final consent to take part in the study, and the other two couples, due to their complex family circumstances, declined to participate. The five couples lived in an East Midlands county of England, with two couples from the second most deprived district and three from the most affluent district within the county.

At the time of recruitment, the mean age of the person living with dementia was 76 years; the mean length since the diagnosis of dementia was just under one and a half years; and the mean score of MMSE was 21. All the participants with dementia lived with other conditions such as arthritis, diabetes, and/or Parkinson's disease and all identified their ethnicity as 'White British' and had heterosexual relationships, as outlined in Table 1.

INSERT TABLE 1 ABOUT HERE 
A pencil sketch of the participating couples is provided below and, in line with the study protocol, all names have been anonymised through the use of pseudonyms:

Couple 1: Mary was diagnosed with Alzheimer's disease in 2010. She and her husband, Steve, had lived in an owned, semi-detached bungalow in a deprived urban area since 1958. They defined their neighbourhood as "what's near you?" and "how far you would go to know people”, including geographically and emotionally close social networks and places.

Couple 2: Patricia had been living with a mixed type of dementia since 2007. She and her husband, Brian, had lived in an owned, large detached house in an affluent area since 2006. The couple's self-defined neighbourhood was shaped by Patricia's social contacts and activities, including their previous home, to maintain a sense of familiarity and belonging.

Couple 3: Diane's Alzheimer's disease was diagnosed in 2009. She and her husband, Dave, had lived in an owned, sizeable bungalow in an affluent village for over 40 years. The couple considered their neighbourhood as "associated virtually with the whole of the village", highlighting the significance of friends and places.

Couple 4: Jonathan had been living with Alzheimer's disease since 2010. He and his partner, Jackie, had lived in an owned, terraced house in a deprived out-of-town area since 1990 . The couple defined their neighbourhood as "the whole suburban area" but, more importantly, identified a 'virtual neighbourhood' where they connected with their family and friends via social media and the internet.

Couple 5: Emily was diagnosed with Alzheimer's disease in 2011. She and her husband, Tim, had lived in a rented, terraced bungalow in a little street of an affluent village since 2001. According to Emily, the couple defined their neighbourhood as "just this little street" which incorporated their significant social ties and places. 
Study design

This study adopted a narrative design within a longitudinal, participatory approach, drawing upon an environmental gerontology perspective on places and spaces while rooted in a naturalism paradigm. Narrative inquiry seeks to study people's experiences as stories (Connelly and Clandinin 2006) and can capture and analyse meaning making in people's lives (Riessman 1993, 2008), including past social status and relationships (Robertson 2010). Additionally, a longitudinal, participatory approach enables people living with dementia to take active roles in research (Hellström et al. 2007) and enhances the authenticity of their stories (Bergold and Thomas 2012; Institute of Development Studies 2017). During the (up to) one-year engagement (see Table 1), the first author conducted 65 home visits and collected over 57 hours of interview data alongside other data sources, including six coconstructed neighbourhood maps, 72 photographs, diaries, 10 demographic questionnaires and field notes containing observations and reflections.

Although participatory mapping was used, this article will, in particular, visually feature participants' lived experiences through photographs to enrich their verbal narratives. During the study, participants were asked to take pictures of the environment that they thought would best represent their neighbourhood and/or were of symbolic meaning in their everyday lives. A disposable camera was provided by the first author to help capture such images or participants could use their own digital camera if they so wished. Consequently, two couples (Mary and Steve, and Emily and Tim) used the disposable cameras and other couples used their own digital cameras. In between the arranged interviews, all the couples in the study photographed significant/personal elements of their self-identified neighbourhood. In subsequent interviews at home with the first author, participants selected the photographs that they felt best represented their neighbourhood and explained the rationale for choosing these specific photographs. This exchange was recorded and helped to inform data analysis. 


\section{Data analysis}

Riessman's (2008) approach to narrative analysis was used, paying particular attention to sequences of action and making sense of experience. Transcriptions and other supplied artefacts were analysed using thematic narrative analysis with the analysis of visual data, e.g. photographs, following Riessman's (2008) three-step approach, namely: i) the production of an image: who the creator and subjects of the image are and where it was made; ii) the content of the image: what the image includes and suggests in the context of the whole storyline; and iii) the reaction of the audience to the image: responses and subsequent responses of initial and later viewers, how stories interweave with the image (p.144).

Data analysis was performed through repeatedly viewing the assembled photographs alongside other qualitative data collected in this study - to evolve relevant concepts inductively and then to identify a sequence of relevant events to contextualise and explain the meanings of the visual data (Riessman 2008). This approach ensured that the most desired convergence was captured and interpreted, especially when diverse sources of data pointed towards the same accounts. For instance, Jonathan and Jackie (couple 4) photographed their local park as a visual representation of a neighbourhood landmark, while the diaries and interview data further explained how often and why they went to this place, with whom, and what it meant to them. This was followed by Patton's (1999) triangulation to compare and cross-check the data gained at different times, and using several qualitative methods within and across cases, to verify and validate the analysis.

\section{Ethical considerations}

Prior to participation, written, informed consent was obtained from all the participants, and process consent (Dewing 2007) was applied at each visit to ensure people living with dementia had capacity to continue in the study. All the interviews took place at participants' 
homes where they felt most comfortable and safe. Ethical issues were carefully considered and woven into the research design, such as if participants became upset or showed signs of distressed during the interviews, they would be treated sensitively and asked if they would like to stop the conversation. Space was left to contact the participant's clinicians for further support if necessary. In the event, no interviews had to be terminated due to distress and no unexpected ethical dilemmas occurred.

Approval to conduct the study was gained from the Nottingham Research Ethics Committee 1 (reference number: 10/H0403/100) and from the relevant NHS Trust Research and Development department (reference number: R.113.11) in line with research governance procedures. Analysis revealed the three themes of: i) 'connecting to people'; ii) 'connecting to places'; and ii) 'connecting to resources' which will now be described in more detail.

\section{Findings}

Theme 1: Connecting to people

Analysis indicated that the participants located 'people' in their neighbourhood, consisting of family members, friends and neighbours. This construction was influenced by regular contact and a sense of belonging developed over time, particularly the ways in which 'people' approached the persons living with dementia and how those actions were viewed and responded by the couples. For example, when connecting to family members, it was the close emotional bonds that enabled the couples to include their wider family members into their neighbourhood. Here, close emotional bonds are seen as a reciprocal process where the person living with dementia, his/her care partner and family members felt connected to one another. 
The close connections between the couples and their family members were the key feature in the storylines of Patricia and Brian (couple 2), Jonathan and Jackie (couple 4), and Emily and Tim (couple 5). As an illustration, for Patricia and Brian, and Emily and Tim, they felt a sense of connection with their family members who provide tailored support to the persons living with dementia with love rather than being driven by a sense of duty. For Patricia and Brian (couple 2), their daughter undertook some responsibilities to support Patricia's care needs, such as washing and setting Patricia's hair and taking her shopping, accompanied by a sense of care. Similarly, Emily and Tim (couple 5) felt that they had close family bonds by frequently meeting up with, and being looked after by, their children. Emily described: "she [one of their daughters] is always ... looking after me kind of thing”, whilst Tim neatly summarised this situation as "the family's important". To illustrate the strong sense of unity the couple felt about their family, they took photographs of having dinner with their family together (photograph 1).

\section{INSERT PHOTOGRAPH 1 ABOUT HERE}

Close emotional connections also occurred remotely as the person living with dementia could interact with family members via the computer. This remote connection led to a virtual dimension to the neighbourhood concept from couple 4, Jonathan and Jackie, and they extended the meaning of a neighbourhood beyond a geographical lived place. Jonathan used Facebook and email to connect with his wider family regularly: "my daughters and sons are all on there [Facebook], my sister and her kids, and I speak to them sometimes, sometimes I just look and see what's on there and who's on there...". It was this frequent contact with 
social ties that formed a cumulative pattern and that gave Jonathan a sense of attachment over time.

When considering a sense of connection within each couple, again, it was their close bonds, but more accurately a sense of 'togetherness' that enabled each couple to look after each other and to maintain connected to their neighbourhood, especially for the person living with dementia. 'Togetherness' was emergent across all the couples. For example, Tim, in couple 5, helped Emily maintain her social contacts by taking her out to meet friends, which also offered a sense of enjoyment for Tim.

Embedded within the narratives of Mary and Steve (couple1), Patricia and Tim (couple 2), Diane and Dave (couple 3), and Jonathan and Jackie (couple 4) was the importance of gaining a sense of group identification and self-worth when connecting with non-family members through regular participation in personalised group-based activities over time. Such feelings motivated these couples to engage in society and so included friends and neighbours in their neighbourhood. This drew attention to how personalised group-based activities had the potential to support social citizenship through promoting shared connection and/or encouraging personal participation and responsibilities. As illustrated in couple 1, Mary and Steve attended the Friendship Club every Friday and interacted with the members whom the couple perceived as "very nice" and similar to them. By attending this Friendship Club, the couple held a sense of purpose for getting 'out and about' and gained a sense of identification and connection with the members, noting that they "hate the evenings [of being] shut away from everybody". They defined this club as part of "what's near" to them. This social engagement also encouraged Patricia (couple 2) to continue her attendance at a monthly Flower Club where she connected with her friend and other members. To denote the positive impact of social connection, Patricia succinctly summarised this as "feeling causes action". By attending such activities, Mary, Jonathan, and Patricia also had an impact on other 
members through their presence at the groups, their contribution to activities, and their influence on group dynamics, all of which helped optimise their role as social citizens.

Moreover, involvement in personalised group-based activities helped gain a sense of selfesteem, particularly present in Diane and Dave's (couple 3) narrative. The couple attended their local committee meetings as part of their roles as committee members and as an act of service to their community. For Diane, while dementia and other conditions affected her ability to participate, the local committees made adaptations to encourage her ongoing involvement and contribution. As such, she continued to commit to the committees with an altered role and responsibilities and to be a valuable member, ultimately maintaining her sense of connectedness and self-confidence. The couple felt the committees were "one of the best things in the village" which gave them "a very good social life" and enabled them to exercise their social citizenship, although they did not have "a lot of time to do other things".

The participants' narratives illustrated that connecting to friends and neighbours over time formed 'neighbourhood support' where people looked after one another through a sense of care and responsibility in a reciprocal process. When connecting to this 'neighbourhood support', all the couples experienced a sense of safety and security and gained practical help, with a more significant effect on the persons living with dementia who were facilitated to continue living independently at home and to be 'out and about' in the neighbourhood. Conversely, the participants could also provide support to others to help sustain the values of the 'neighbourhood support'. For example, Mary and Steve's (couple 1) neighbour, Ben, helped with their plumbing issues and another neighbour, Tom, pushed the 'wheelie bin' up their sloping drive each week. Mary and Steve regularly saw and spoke to their neighbour Fiona and if they did not see her for a few days they would telephone her to check if 'she was ok', and vice versa. Through this reciprocal process, the couple were not passive recipients 
but active contributors to their neighbourhood, illustrating what they could do and continue to do for neighbours and friends.

This reciprocal process was even more apparent in couple 4, Diane and Dave's narrative. Over the years, they had significantly contributed to the local committees and, in return, the residents provided care and support for them. As an illustration, their immediate neighbour was named on Diane's emergency contact list alongside Dave and the family. In this case, the neighbour accepted a degree of responsibility for crisis management which enabled Diane to feel safe and secure and enhanced her family's confidence in her staying at home alone, for short periods if needed.

Support was also provided in a more nuanced and subtle way that aimed to protect the person living with dementia's autonomy and connections to people. This was demonstrated in couple 2, Patricia and Brian's narrative in that a local shop keeper, who was aware of Patricia's diagnosis, kept an eye on her when she went to, or passed by, his shop. To present the significant role that the local shop keeper played in the couple's experiences of living with dementia, they pictured the local store as shown in photograph 2 .

\section{INSERT PHOTOGRAPH 2 ABOUT HERE}

This caring action helped Patricia to maintain her independence and presence 'out and about' in the neighbourhood and reassured Brian's confidence in her going out to get the newspapers or for a short walk on her own. 
Theme 2: Connecting to places

Analysis of the data suggested that the participants located 'places' where they had regular contact and emotional attachments in their neighbourhood. Such attachments derived from cumulative and interactional experiences, and especially through constant place-making and re-making processes. These processes affected, and were affected by, personal biographies. Hence, 'places' were not simply physical spaces, but, instead, captured life stories and presented aspects of the self through the life course. This comprised regularly visited and remembered places with 'home' being a central, starting point for neighbourhood connectivity.

Home was a place where all the couples personalised their living environment with objects that represented important life events and held meanings drawn over the life course. These meaningful objects represented aspects of biography. As an illustration, Emily and Tim (couple 5) had a clock that gave the couple a great deal of pleasure when it played Beatle's music on the hour and triggered memories about their holiday in America where they bought the clock. Hence, this particular clock not only fulfilled a functional purpose, but it also provided a means of personal expression and captured life stories. In Mary and Steve's (couple 1) home, their marriage photographs were on the sitting room wall. These photographs prompted Mary's memory about their wedding day as she happily shared: “it was all arranged at the church, we got married at the village church here ... when we used to go out for a walk, we used to say, 'yes, we'll get married there."' The photographs brought the couple's past into the present and facilitated a sense of connections beyond the home.

Home objects also evoked personal responses and held unique meanings, so altering the selfevaluation of 'a sense of being in place' in time. Central to this was the personal interpretation of the meanings of the home and the transformation of home objects into 
treasured possession. For example, Jonathan, (couple 4) hand-built most of the furniture in the home, giving it both a personal touch and a way for him to project a favourable image of himself as a craftsman. As seen in photograph 3, Jonathan was pictured sitting in the kitchen built by him, illustrating a sense of personal pride and identity.

\section{INSERT PHOTOGRAPH 3 ABOUT HERE}

In contrast, Patricia (couple 2) used to be an accomplished pianist and her piano was kept in her 'office' at home. However, as her abilities declined, this instrument came to represent frustration and loss, reminding Patricia that she was no longer the person she used to be. Her frustration and sadness were expressed through playing the piano less frequently, as her husband Brian observed: “... playing the piano is becoming more of a hardship for her, more of too many mistakes ... because of that she is playing it less and less and less ..." Arguably, Patricia's response played a crucial role in reducing her connection with this treasured possession and disrupted her feeling of connectedness to her home.

The perception of home was also affected by everyday lived experience. Pleasurable experiences helped to retain connection to the current place for longer and led to positive views when compared to unpleasant living experiences. This influenced personal interpretations about 'being in place'. To illustrate this further, there was a stark contrast between Mary and Steve's (couple 1) experience and Patricia and Brian's (couple 2). Mary and Steve expressed a great sense of satisfaction with, and positive experience of living in, their home: “it [buying the bungalow]'s the best thing we have done in our life ... we are happy, we have got everything we want". This perception enabled the couple to feel a sense 
of being at home and importantly to perceive it as a 'safe' place where they could protect themselves from the fear of crime in the local area: "we won't step out that [front] door in the dark". So, while their connection to the neighbourhood was temporarily disrupted at night by their feeling of fear, overall, they retained a sense of safety and felt connected to their neighbourhood. In contrast, Patricia and Brian's (couple 2) memories of their home were dominated by their unpleasant memories of Brian's cancer diagnosis and the development of Patricia's dementia, both coming soon after moving in. It was these cumulative, negative experiences that interrupted Patricia's connection and affected her sense of familiarity and belonging to the home and neighbourhood as she forcibly stated: "we live here and it's not a place I know...” The person-home relationship was at the centre and heart of connecting to spaces and places outside the front door.

Incorporated in all the participants' narratives was their frequent interactions with specific places, and over time they became familiar with, assigned meanings to, and developed attachments to, these places. This layering of the place-making process over time enabled places to become a landscape of captured memories. All the participants spoke about 'outdoor spaces' which consisted of public parks and private gardens. Embedded in Jonathan and Jackie's (couple 4) narrative was the significance of the local park, which was not only a physical space, but also an important place of connection to nature and activity. They went to the local park daily to walk their dog and hence became intimately familiar with this space which provided many enjoyable experiences. The couple photographed the park and their dog (photograph 4) to draw attention to the green space and soothing environment as well as the companionship the dog offered, all of which portrayed a "very important" part of their daily life and neighbourhood connections. 


\section{INSERT PHOTOGRAPH 4 ABOUT HERE}

The garden at home was another significant place where all the participants had a physical and emotional investment and gained a sense of enjoyment as this space acted as a connector between the home and the neighbourhood and transcended a sense of connection from inside to outside the front door. Jonathan (couple 4), for instance, built a fish pond in his garden so that he and his wife could spend their time together, often having a cup of tea whilst feeding the fish. This life event strengthened their bonds to the home and beyond. Similarly, Steve (couple 1), built a summer house in his garden and worked hard to maintain it throughout the year. As such, Steve and Mary could stay in their garden to enjoy the green space which acted as a point of connection to their neighbourhood. Together, these life events contributed to the couples' life histories and transferred the everyday spaces into meaningful, personalised places where they spent their time together and felt 'a sense of being in place'. Access to outdoor spaces also facilitated a sense of connection to the neighbourhood from a social perspective. For Mary and Steve (couple 1), by simply sitting in the garden they could clearly see the local secondary school where school children sometimes played sports on the playing field opposite to their home. It was the importance of the sounds of life and visual impression that enabled the couple to feel connected to their neighbourhood. For Emily and Tim (couple 5), a specific feature in their garden - a lilac tree - represented a sense of friendship as Emily shared: "my friend brought it for me for my seventieth birthday".

In discussing neighbourhood connections, access to 'built places' became important and referred to buildings where the couples had regular contact, such as local shopping centres with 'going shopping' identified as a favourite activity. This seemingly mundane and regular chore was important to the participants in terms of their social engagement and autonomy, 
and through which they could go out to meet and talk to others, have a measure of exercise, and choose the goods they wanted. As Jackie (couple 4) enthusiastically shared: "I love shopping!"

In connecting to places, it was not all about the 'here and now'. Remembered places in the neighbourhood were shared or longed for. As presented in couple 2, Patricia and Brian felt that their present home and neighbourhood was "friendly but fairly remote". It was this 'remote' feeling that motivated both Patricia and Brian to bring their previous house, where they had lived for 27 years, into their present neighbourhood. Brian perceived this past home as "much more influential and important than the general community" and Patricia reflected that:

Lovely ... it was just perfect really because they weren't noisy neighbours but you could go over and knock on the door and say, 'can you help me out?' ... we met up in different places ... where you all gather for concerts and things... a town hall sort of thing.

In Emily's (couple 5) narrative, the housing estate was identified as a place of importance as it was built on the site of the old shoe factory where her, now departed, best friend used to work. Again, this remembered place became an important part of her current neighbourhood.

Theme 3: Connecting to resources

To enable independent living and to sustain neighbourhood connections, analysis of the data revealed that the couples actively sought support and used various tools to enhance their strengths and agency, especially for the persons living with dementia. These resources related to home environment, neighbourhood environment and local care services. Indeed, the participants proactively changed their home environment through relocation to enhance their 
living experiences. As shown in the narratives of Patricia and Brian (couple 2), Diane and Dave (couple 3), and Emily and Tim (couple 5), relocation to a bungalow or smaller, more practical house, allowed them to easily access rooms around the home and the local amenities. However, relocation did not always lead to positive outcomes, but, instead, it might be at the expense of connecting with social ties. This was evident in couple 2, Patricia and Brian's storyline in that, although accessing support seemed to be the priority for their everyday living, at an emotional level, feeling socially connected was more important for Patricia and affected her view of 'a sense of being in place'. Relocation challenged Patricia to establish social connection within the present neighbourhood, and as such, she travelled through time to emotionally engage with the past and gain a sense of familiarity and belonging.

In addition to relocation, all the participants living with dementia adapted support aids to enhance their abilities in performing tasks. As Jonathan's (couple 4) narrative demonstrated, on bad days he was unable to stand for long periods due to his Parkinson's disease. To overcome this, Jonathan bought two stools - one for the workroom and the other for the kitchen - which assisted him in remaining engaged with his leisure activity (carpentry) and made it easier for him to undertake household tasks as he shared: “[it's]easier to do the washing up". Similar creative and adaptive practices were adopted by the other participants living with dementia, Mary, Patricia, Diane, and Emily who used a walking stick or a pusher (a light four-wheeled walking frame) when moving around their homes. This change positively affected daily living and independence, as Mary shared: "I can walk down there [the hall], I've got a pusher [walking aid with wheels], I've got the sticks, so I've got everything I need in that respect”.

Support aids might not always be sufficient to equip the persons living with dementia to undertake activities of daily living, this was where home modification came into play. Indeed, 
Emily and Tim (couple 5) requested modification to their bathroom to enable Emily to maintain a certain level of independence and retain a sense of self:

Emily: I feel very embarrassed when I do make a mess, yeah, that's not me, never has been ... the only thing that worries me is me going to the toilet.

Tim: It will be better when we got a proper shower room ... a special seat with wheels on.

In connecting to resources, technologies played a significant role as demonstrated by Patricia and Brian (couple 2), Diane and Dave (couple 3), and Jonathan and Jackie (couple 4). Here, technologies referred to an emergency alarm, a digital life story book created using an iPad, and a computer that enabled the persons living with dementia to connect with their social ties and thereby their neighbourhood. These devices also provided a sense of safety and security and helped stimulate memory. For example, Diane's (couple 3) adoption of the emergency alarm enhanced her and her family's confidence when she stayed at home alone as it alerted four named persons at a time of emergency. Patricia (couple 2) used a life story book, which Brian created using an iPad to capture family members' photographs that triggered biographical and neighbourhood memories. As described previously, Jonathan (couple 4) used an internet connected computer to contact his family or friends daily, leading to the virtual dimension of their neighbourhood construction.

It was worth noting that, to ensure successful use of technology, the tasks needed to be meaningful, tailored, and sensitive to the person living with dementia's capabilities and biography. In addition to the life story book, another successful example was that Patricia (couple 2) enjoyed using the iPad to play simple word-based online games on her good days. Although playing games only lasted for very short periods, it enabled Patricia to continue her biographical interest as she used to love completing crossword puzzles. Not all uses of 
technology were successful, for example, where Brian used the iPad to produce a telephone directory to story their family and friends' telephone numbers, he was hoping this electronic telephone book would ease Patricia into connecting to her social networks as and when she wished. However, despite Brian repeatedly demonstrating to Patricia on how to find this information on the iPad, her impaired cognitive functioning - reasoning and memory prevented her from understanding alphabetical order, causing her to be frustrated by the technology. This indicated that using technology beyond the person living with dementia's capability would not lead to the desired outcome, but, instead, added stress to both the person and the carer, thereby raising an ethical issue around its use in practice.

When considering the neighbourhood environment, as suggested above, an enabling environment was a key feature in Jonathan and Jackie's (couple 4) storyline and enabled them to maintain a sense of connection to their neighbourhood and of continuity in their lives, moving from the virtual to the practical aspect of their neighbourhood. As such, they were well prepared to meet their everyday needs, as Jackie shared:

It's the flat ... I'm slightly disabled and he's getting quite bad and everything's close, so if we can't drive any more then we have everything round us that we need. The doctor's is just up the road, the chemist is just round the corner, the post office, the banks, and everything we need is accessible ...

Accessing an enabling social environment was of equal importance; this was predominantly present in couple 2, Diane and Dave's narratives. As discussed earlier, it was the local committees that offered the couple a measure of equality and provided Diane with flexible adaptions and a suitable environment to better support her when it came to contribute to the locality and engage with social events. Although the committees equipped Diane with rights and responsibilities and made adaptations to enable her continuing participation, she was 
fully aware of her diminishing involvement and contribution. Nevertheless, through continuing engagement in the committees, Diane and Dave maintained their connection with their social networks and were continually involved in local events, for instance, the games afternoon which took place once a year in the village hall. Usually, around 50 members attended this event which would last for a couple of hours. The couple captured this social event, as seen in photograph 5, to illustrate their friends with whom they met on a regular basis and to draw attention to their in-the-moment happiness. Therefore, it was the significance of the local committees that promoted the couple's social citizenship, especially for the person living with dementia.

\section{INSERT PHOTOGRAPH 5 ABOUT HERE}

To remain living at home and to meet health needs, timely access to quality care services was increasingly important. However, Mary and Steve (couple 1), Patricia and Brian (couple 2), and Diane and Dave (couple 3) experienced challenges in accessing local services, including difficulties in booking an appointment, long waiting times, and appointments being delayed or cancelled. Additionally, Brian raised a significant concern about their quality:

The services in this area are poor, she [Patricia] had seen in the last year her psychologist may be twice ... we need help and I'm happy to pay for help, but nobody would come in and do the assessment [to determine the level of care Patricia needs] which enables me to buy the help ... I'm annoyed, and the local services are poor.

To point out the importance of local care services, the couple photographed Patricia's surgery as a crucial place in their neighbourhood as shown in photograph 6 . 


\section{INSERT PHOTOGRAPH 6 ABOUT HERE}

Interestingly, Brian repeatedly mentioned "the services are poor" in his conversation, highlighting his frustration, as a lack of timely access to good quality services was detrimental for all aspects of their lives, helping maintain Patricia to live at home while reducing Brian's stress, thereby stabilising their lives as a couple.

\section{Discussion}

This article offers in-depth insights into how people living with dementia balance everyday opportunities and limitations to retain their social health under a biographical phenomenon within an East Midlands area of the UK. The three themes of 'connecting to people', 'connecting to places' and 'connecting to resources' also reveal the significance of placemaking and re-making where the couples, and especially the persons living with dementia, had skills and strengths to influence and contribute to their neighbourhood which, in return, could better support their needs. It is this important understanding of place-making in the context of dementia that supports an asset-based approach to a neighbourhood model and promotes social citizenship for people living with dementia, as well as moving away from the traditional biomedical model focusing upon deficit and loss.

This study presents real-life examples to Bartlett and O'Connor's $(2007,2010)$ approach to locating social citizenships in a broader social practice though 'rights', including: i) opportunities for growth; ii) to have one's self recognized in a holistic way beyond simply that of a person living with dementia; iii) to retain purpose in one's life irrespective of 
diagnosis; iv) to participate as an active agent in one's life; and more significantly, v) to create a sense of solidarity and belonging with others. For instance, the findings indicated that a 'neighbourhood' was a place where the couples lived, but more significantly was a product of their connections with 'people' and 'places' and their access to 'resources', coupled with their interpretation of 'being in place'. Our findings also endorse the position of the 'lived' neighbourhood (Ward et al. 2018) where people living with dementia can use their potential and capabilities to offset the limitation they encounter. In addition, the three themes draw attention to participants' inside views of the world outside through illustrating their feelings of belonging and connection to their neighbourhood, thereby enriching and advancing the concept of 'neighbourhood' being a lived place within a flexible and fluid geographical boundary.

The presented findings also indicated the meaning and construction of neighbourhood, which was a combination of a place where the couples lived, a product of their interactions with 'people', 'places' and 'resources' through time, and a result of their interpretations of 'a sense of being in place'. This complex, fluid construction draws attention to personal biographies, highlighting the significance of biographical connectivity to the neighbourhood in affecting the lived experience of dementia. This biographical connectivity derives from a cumulative effect of connectedness to the neighbourhood and a feeling of 'being in place' through frequent interactions with social and physical environments, as well as access to local resources within and through time. It is the desire to stay connected that motivated the couples, particularly the persons living with dementia, to constantly identify opportunities, such as participating in personalised group-based activities and adapting various resources, to strength their abilities and to enhance their potentials. Ultimately, this acted to stabilise or to renew person-neighbourhood relationships. The desire for stability encourages an ongoing 
place-making and remaking process which is shaped by, and reshapes, personal biographies and affects 'a sense of being in place'.

It is this importance of the biographical lens that facilitates a closely intertwined process between disruption and flow when connecting to the neighbourhood; the key to this is a sense of continuing person-neighbourhood relationships. This biographical lens not only facilitates an understanding of the interactions between the participants and their neighbourhoods, but also reiterates a transactional perspective of person-environment relationships (Brorsson et al. 2011) in dementia research. It also evokes a fluid notion of personal biographies and neighbourhood through time. In addition, biographical connectivity to the neighbourhood echoes Meijering et al. (2017) idea of a bio-geographical disruption and flow, highlighting:

The extent to which relational experiences of space/place are disrupted by changes in the life course arising from disability [stroke] as well as on how taken for granted embodied states have to be renegotiated at any other place anew (p.7).

Although bio-geographical disruption can be experienced after the onset of the condition, the final purpose is to regain a sense of bio-geographical flow or create a new version of this flow (Meijering et al. 2017). Furthermore, the concept of biographical connectivity drawn from the three themes, advances Meijering et al. (2017) claim by recognising the aspiration for stabilising person-neighbourhood relationships that drives the couples, and in particular the people living with dementia, to overcome disruptions and to endorse existing, or to establish alternative, connections.

When connecting to 'people' and 'places', it is the significance of a sense of belonging and attachment gained through a reciprocity process and through continuing place-making and remaking, respectively, to enable the participants and especially the persons living with dementia to feel 'being in place'. The finding echoes the existing knowledge of Rowles' 
(1983) 'physical insideness', 'autobiographical insideness', 'social insideness' and 'social credit', and reiterates the concept of 'place attachment' (Hammitt, Backlund and Bixler 2004; Kyle et al. 2004; Low and Altman 1992). Additionally, this article enhances these concepts by highlighting personal biographies and by presenting rich insights into how the participants interact with, and their subjective perceptions about, their neighbourhoods. The process of 'connecting to people' also values interdependence and recognises the reciprocity of giving and receiving processes in care practice (Brannelly 2011) and beyond. When connecting to 'resources' this influences how the persons living with dementia interacted with their neighbourhood and their person-environment experiences and so plays a significant role in bringing the equal rights of people living with dementia to the fore and supports the social model of disability with human rights principles (Mental Health Foundation 2015).

Finally, for people living with dementia and their care partners, the heart of the 'connected neighbourhood' is the maintenance, or renewal, of biographical continuity to the spaces, places and people where everyday life is played out whilst accessing suitable resources to facilitate agency. For environmental and town planning, attention should be paid to these factors in addition to the six design principles for dementia-friendly neighbourhoods recommended by Mitchell and Burton (2010), namely familiarity, legibility, distinctiveness, accessibility, comfort, and safety.

\section{Study limitations}

Whilst no claims of representativeness are made, the sample of this study was small, and all the participants were White British, living in one East Midlands county of England. This suggests scope to further develop the themes presented in this paper through a larger sample size, emphasising other geographical areas of the UK, and considering alternative ethnic 
backgrounds to understand how a sense of connectedness maps on to differing cultural identities within the UK. Secondly, the sample did not cover those living alone with dementia who may have different experiences and meanings attached to connected neighbourhoods.

\section{Conclusion}

This study has emphasised the impact of the neighbourhood upon people living with dementia and their care partners, but more importantly, points out a strength-based approach to place-making where the couple can positively contribute to their neighbourhood and influence community dynamics. This study is also an early attempt to shape the traditional approach to dementia-friendly communities through a social citizenship lens and to support a 'bottom-up' approach to neighbourhood constructions where the intersections of the person's life to their neighbourhood lays the foundation for reciprocal support and enablement. This study thereby adds to the growing interest in citizenship-based approaches to neighbourhoodlevel research and person-environment relationship. Moreover, the notion of viewing the connected neighbourhood through a biographical lens allows policy makers to think about embedding a social citizenship-based approach for people living with dementia and their care partners within a multifaceted neighbourhood context. 


\section{References}

Alzheimer's Society (2013). Building dementia-friendly communities: A priority for everyone. Alzheimer's Society, London.

Alzheimer's Society (2017). What is dementia? Alzheimer's Society, London.

Baker, R. (1968). Ecological Psychology. Stanford University Press, Stanford, CA.

Bartlett, R. (2014). Citizenship in action: the lived experiences of citizens with dementia who campaign for social change, Disability and Society, 29, 1291-1304.

Bartlett, R. and Brannelly, T. (2018). Life at home for people with a dementia. Routledge, London.

Bartlett, R. and O'Connor, D. (2007). From personhood to citizenship: Broadening the lens for dementia practice and research. Journal of Ageing Studies, 21, 107-118.

Bartlett, R., and O'Connor, D. (2010). Broadening the Dementia Debate: Towards Social Citizenship. Policy Press, London.

Bergold, J. and Thomas, S. (2012). Participatory research methods: A methodological approach in motion. Forum Qualitative Sozialforschung / Forum: Qualitative Social Research, 13, Art.30.

Blackman, T. (2006). Placing Health: Neighbourhood Renewal, Health Improvement and Complexity. The Policy Press, Bristol.

Brannelly, T. (2011). That others matter: the moral achievement-care ethics and citizenship in practice with people with dementia. Ethics and Social Welfare, 5, 210-216.

British Psychological Society [BPS] (2015). Dementia and People with Intellectual Disabilities: Guidance on the assessment, diagnosis, interventions and support of people with intellectual disabilities who develop dementia. BPS, Leicester.

Brittain, K.R., Corner, L., Robinson, L. and Bond, J. (2010). Ageing in place and technologies of place: The lived experience of people with dementia in changing social, physical and technological environments. Sociology Health Illness, 32, 272-87.

Brorsson, A., Ohman, A., Lundberg, S. and Nygard, L. (2011). Accessibility in public space as perceived by people with Alzheimer's disease, Dementia: the international journal of social research and practice, 10, 587-602.

Connelly, F. and Clandinin, D. (2006). Narrative inquiry. In Green, J., Camilli, G. and Elmore, P. (Eds.). Handbook of complementary methods in education research (pp. 375-385). Lawrence Erlbaum, Mahwah, NJ. 
Dempsey, N. (2007). Are high quality neighbourhoods socially cohesive? Methodological challenges of unpacking multidimensional concepts. Paper presented at the EURA 10th Anniversary Conference, University of Glasgow, Scotland.

Department of Health (2012). Prime Minister's Challenge on Dementia: Delivering major improvements in dementia care and research by 2015. Department of Health, London.

Department of Health (2015). Prime Minister's Challenge on Dementia 2020. Department of Health, London.

Dewing, J. (2007). Participatory research: A method for process consent with persons who have dementia. Dementia: the international journal of social research and practice, 6, 11-25.

Duggan, S., Blackman, T., Martyr, A. and van Schalk, P. (2008). The impact of early dementia on outdoor life: A ‘shrinking world'? Dementia: the international journal of social research and practice, $7,191-204$.

Folstein, F. M., Folstein, E. S. and McHugh, R. P. (1975). Mini-mental state: A practical guide for grading the cognitive state of patients for the clinician. Journal of Psychiatric Research, 12, 189-198.

Górska, S., Forsyth, K. and Maciver, D. (2018). Living with dementia: A meta-synthesis of qualitative research on the lived experience. Gerontologist, 5893, 180-196.

Hammitt, W., Backlund, E. and Bixler, R. (2004). Experience use history, place bonding and resource substitution of trout anglers during recreation engagement. Journal of Leisure Research, 36, 356-378.

Hellström, I., Nolan, M., Nordenfelt, L. and Lundh, U. (2007). Ethical and methodological issues in interviewing persons with dementia. Nursing Ethics, 14, 608-619.

Harding, A. J. E., Morbey, H., Ahmed, F., Opdebeeck, C., Wang, Y. Y., Williamson, P., Swarbrick, C., Leroi, I., Challis, D., Davies, L., Reeves, D., Holland, F., Hann, M., Hellström, I., Hydén, L. C., Burns, A., Keady, J. and Reilly, S. (2018). Developing a core outcome set for people living with dementia at home in their neighbourhoods and communities: Study protocol for use in the evaluation of non-pharmacological communitybased health and social care interventions, Trials, 19, 1-24.

Huber, M., Knottnerus, J.A., Green, L., van der Horst, H., Jadad, A.R., Kromhout, D., Leonard, B. and Smid, H. (2011). How should we define health? BMJ, 343, d4163.

Institute of Development Studies (2017). About Participatory Methods. Available: http://www.participatorymethods.org/page/about-participatory-methods [Accessed 10th May 2018].

Keady, J., Campbell, S., Barnes, H., Ward, R., Li, X., Swarbrick, C., Burrow, S. and Elvish, R. (2012). Neighbourhoods and dementia in the health and social care context: A realist 
review of the literature and implications for UK policy development. Reviews in Clinical Gerontology, 22, 150-163.

Kelly, F. and Innes, A. (2013). Human rights, citizenship and dementia care nursing. International Journal of Older People Nursing, 8, 61-70.

Kyle, G., Graefe, A., Manning, R. and Bacon, J. (2004). Effect of involvement and place attachment on recreationists' perceptions of setting density. Journal of Leisure Research, 36, 209-231.

La Gory, M., Ward, R. and Sherman, S. (1985). The ecology of ageing: Neighbourhood satisfaction in an older population. The sociological quarterly, 26, 405-418.

Low, S. M. and Altman, I. (1992). Place attachment: A conceptual inquiry. In Altman, I. and Low, S.M. (Eds.), Place Attachment (pp.1-12). Plenum, New York, NY.

Massey, D. (1994). Space, place and gender. University of Minnesota Press, US.

Meijering, L., Lettinga, A.T., Nanninga, C.S. and Milligan, C. (2017). Interpreting therapeutic landscape experiences through rural stroke survivors' biographies of disruption and flow. Journal of Rural Studies, 51, 275-283.

Mental Health Foundation (2015). Dementia, Rights and the Social Model of Disability. Mental Health Foundation, London.

McGovern, J. (2016). Capturing the significance of place in the lived experience of dementia. Qualitative Social Work, 16, 664-679.

Mitchell, L. and Burton, E. (2010). Designing dementia-friendly neighbourhoods: Helping people with dementia to get out and about. Journal of Integrated Care, 18, 11-18.

National Institute for Health and Care Excellence [NICE]. (2006). Dementia: supporting people with dementia and their carers in health and social care (CG42). NICE, London.

Office of the Deputy Prime Minister (2002). Living places: cleaner, safer, greener. Alzheimer's Society, London.

O'Connor, D. and Nedlund, A.C. (2016). Editorial introduction: special issue on citizenship and dementia. Dementia: the international journal of social research and practice, 15, 285288.

Odzakovic, E., Hellström, I., Ward, R. and Kullberg, A. (2018) 'Overjoyed that I can go outside': Using walking interviews to learn about the lived experience and meaning of neighbourhood for people living with dementia. Dementia, Online Firstview.

Oxoby, R. (2009). Understanding social inclusion, social cohesion, and social capital. International Journal of Social Economics, 36, 1133-1152. 
Patton, M.Q. (1999). Enhancing the quality and credibility of qualitative analysis. Health Services Research, 34, 5 (Part II), 1189-1208.

Peace, S. (2013). Social interactions in public spaces and places: A conceptual overview. In Rowles, G. and Bernard, M. (Eds.), Environmental gerontology: Making meaningful places in old age (pp. 25-49). Springer, New York, NY.

Pezzotti, P., Scalmana, S., Mastromattei, A. and Lallo, D. D. (2008). The accuracy of the MMSE in detecting cognitive impairment when administered by general practitioners: A prospective observational study. BMC Family Practice, 9, 1-11.

Pierce, J., Martin, D. T. and Murphy, J. T. (2011). Networked place-making: the networked politics of place. Transactions of the British Institute of British Geographers, 36, 54-70.

Riessman, C. K. (1993). Narrative Analysis. Sage, London.

Riessman, C. K. (2008). Narrative methods for the human sciences. Sage, London.

Robertson, J. M. (2010). Making sense and finding meaning: Comparing narratives of older people with dementia and carers about the quality of an ordinary life. University of Stirling, Stirling.

Rowles, G. (1983). Place and personal identity in old age: Observations from Appalachia. Journal of Environmental Psychology, 3, 299-313.

Rowles, G. and Bernard, M. (2013). Environmental gerontology: making meaningful places in old age. Springer, New York, NY.

Satariano, W. (2006). Ageing, health, and the environment: An ecological model. In Satariano, W. (Ed.). Epidemiology of Ageing: An Ecological Approach (pp. 39-84). Jones and Bartlett, Berkeley, CA.

Tampubolon, G., Nazroo, J., Keady, J. and Pendleton, N. (2018). Dementia across local districts in England 2014-2015. International Journal of Geriatric Psychiatry, 33, 11271131.

Taylor-Gooby, P. (2008). Reframing social citizenship. Oxford University Press, Oxford.

Tranvåg, O., Petersen, K. and Nåden, D. (2015). Relational interactions preserving dignity experience: Perceptions of persons living with dementia. Nursing Ethics, 22, 5, 577-593.

Vernooij-Dassen, M. and Jeon, Y.H. (2016). Social health and dementia: the power of human capabilities, International Psychogeriatrics, 28, 701-703.

Ward, R., Clark, A., Campbell, S., Graham, B., Kullberg, A., Manji, K., Rummery, K. and Keady, J. (2018). The lived neighbourhood: Understanding how people with dementia engage with their local environment. International Psychogeriatrics, 30, 867-880. 
Wiersma, E. and Denton, A. (2016). From social network to safety net: Dementia-friendly communities in rural northern Ontario. Dementia: the international journal of social research and practice, 15, 51-68.

World Health Organisation (2017). Global action plan on dementia on the public health response to dementia 2017-2025. World Health Organisation, Geneva.

World Health Organisation and Alzheimer's Disease International (2012). Dementia: A public health priority. World Health Organisation, London. 